\title{
ESTUDIO EXPERIMENTAL: MANEJO DEL METISOPRINOL EN PACIENTES CON COVID-19
}

\author{
Borges Migled ${ }^{1}$, Borges Migledys ${ }^{2}$, Borges José $e^{3}$, Bastidas, Rosangel ${ }^{4}$. \\ https://orcid.org/0000-0001-6053-0861 1', https://orcid.org/0000-0001-6941-05672, \\ https://orcid.org/0000-0002-8560-21603, https://orcid.org/0000-0003-3437-50814 \\ grupometisoprinol@gmail.com \\ Consultorio médico y asociados \\ Guayaquil-Ecuador
}

Recibido (13/07/20), Aceptado (28/07/20)

\begin{abstract}
Resumen: El covid-19 es una enfermedad caracterizada por presentar síndrome de dificultad respiratoria aguda y disfunción multisistemica. El presente ensayo clínico aleatorio controlado de diseño experimental se realizó con la finalidad de demostrar la eficacia del metisoprinol en el manejo antiviral alternativo del covid 19, en vista de no existir un tratamiento efectivo comprobado en la actual pandemia mundial decretada por la OMS. Se evaluó una población de 60 pacientes, distribuida en grupos de 30 (grupo experimental y un grupo control) de cualquier edad y sexo con comorbilidades controladas, los cuales presentaron signos y síntomas de SARS-CoV-2 y S02 mayor de 90\% respirando aire ambiente en fase clínica menor de 15 días asistidos en consulta médica a domicilio en la ciudad de Guayaquil, Ecuador entre el periodo de marzo y abril de 2020. Dicho estudio se desarrolló para determinar un protocolo piloto que genere menos efectos adversos, evite complicaciones médicas en pacientes sintomáticos y revierta el cuadro clínico e imagenológico. Se demostró por cálculo de riesgo relativo la posibilidad casi nula de persistir signos y síntomas, así como la presencia de lesiones pulmonares en controles imagenológicos en un $03.33 \%$ y reactividad rRT-PCR del $10 \%$ tratados con metisoprinol.
\end{abstract}

Palabras Clave: COVID-19, SARS-CoV-2, Metisoprinol.

\section{EXPERIMENTAL STUDY: MANAGEMENT OF METISOPRINOL IN PATIENTS WITH COVID-19}

\begin{abstract}
Covid-19 is a disease characterized by presenting acute respiratory distress syndrome and multi-system dysfunction. The present randomized controlled clinical trial of experimental design was carried out in order to demonstrate the efficacy of metisoprinol in the alternative antiviral management of covid 19, in view of the fact that there is no proven effective treatment in the current global pandemic decreed by the WHO. A population of 60 patients, distributed in groups of 30 (experimental group and a control group) of any age and sex with controlled comorbidities, who presented signs and symptoms of SARS-CoV-2 and S02 greater than $90 \%$ breathing air, was evaluated. environment in a clinical phase of less than 15 days attended at home medical consultation in the city of Guayaquil, Ecuador between the period of March and April 2020. This study was developed to determine a pilot protocol that generates fewer adverse effects, avoiding medical complications in symptomatic patients and reverse the clinical and imaging picture. The almost null possibility of persisting signs and symptoms was demonstrated by calculation of relative risk, as well as the presence of lung lesions in imaging controls in $03.33 \%$ and $10 \%$ rRT-PCR reactivity treated with metisoprinol.
\end{abstract}

Keywords: COVID-19, SARS-CoV-2, Metisoprinol. 


\section{I.INTRODUCCIÓN}

La Enfermedad por Coronavirus (COVID-19), es conocida como coronavirus del síndrome respiratorio grave agudo (Severe Acute Respiratory Syndrome coronavirus, SARS-CoV-2) de origen zoonótico y transmisión entre humanos principalmente por vía respiratoria, detectada inicialmente en la ciudad de Wuhan, provincia de Hubei, China, extendiéndose a otras ciudades de este país y luego a otros países de Asia, Europa, África, Norte América y más recientemente en Latinoamérica convirtiéndose en una pandemia mundial anunciado por la OMS. Su presentación en los pacientes varía ampliamente desde aquellos que se encuentran asintomáticos como los que incluyen síndrome de dificultad respiratoria aguda hasta disfunción multisistemica [1]-[7]. Se ha observado mayor incidencia de mal pronóstico cuando hay la asociación de factores de riesgos (inmunológicos, cardiovasculares, endocrinas y patologías respiratorias crónicas) [8]-[10]. Sin embargo, en los últimos estudios se ha reportado una asociación de muerte súbita y eventos tromboembólicos o descargas de citoquinas en pacientes de edades pediátricas y adultos jóvenes sin comorbilidades. El diagnóstico de laboratorio reside fundamentalmente en la prueba de la reacción en cadena de polimerasa por transcriptasa reversa de tiempo real (rRT-PCR) y hallazgos de imágenes (radiológico, tomográficos y ecográficos) [6]-[10].

La población afectada en Ecuador es alarmante, ubicándose el foco de contagio con mayores casos a principios de marzo en la provincia de Guayas desde su inicio 29/02/2020 hasta el corte 30/03/2020 se presentó 1396 contagiados y 38 fallecidos, información proporcionada por el Instituto Nacional de Investigación en Salud Pública (INSPI) en conjunto con el Comité de Operación de Emergencia Nacional, Servicio Nacional de Riesgo y Emergencia [11]. Por ello es necesario identificar un protocolo piloto que genere menos efectos adversos, evite complicaciones médicas en pacientes sintomáticos y revierta el cuadro clínico e imagenológico. En ausencia de terapia efectiva comprobada, el tratamiento experimental actual se enfoca en el uso de corticoides de acción rápida, hidroxicloroquina, soporte ventilatorio invasivo y no invasivo, azitromicina, nitazoxanida, plasma hiperinmune, antirretrovirales (remdesivir, ritonavir, lopinavir, tocilizumab) [8]-[12].

\section{II.DESARROLLO}

El metisoprinol (MET) es un complejo de inosina con tres moléculas de dimetil amino isopropanol [13] con acción antiviral e inmunomoduladora [14]. Este fármaco presenta efecto inmunoestimulante en las citoquinas IL2, IFN y regulador inhibitorio en las cito- quinas FNT e IL10 [14]. Además, suprime la síntesis viral de ARN viral e incrementa "in vitro" la respuesta inmunitaria de linfocitos $\mathrm{T}$, linfocitos $\mathrm{B}$ y con ello la producción de inmunoglobulinas, natural killer y macrófagos [14].

Aunado a lo anterior, el metisoprinol favorece en la célula huésped la producción de la síntesis de proteínas y ácidos nucleicos, preserva la estructura, función y refuerza los puentes de hidrógenos de los polirribosomas celulares. Estos fenómenos constituyen una real y eficaz defensa contra ADN y ARN viral, porque impide la replicación viral, conserva la integridad histológica y funcional de la célula humana. Actúa en infecciones virales tales como Herpes Simple tipo 1 y 2, Herpes Zoster, enfermedades eruptivas de la infancia, panencefalitis esclerosante subaguda y laringotraqueitis. Es rápidamente metabolizado, excretándose casi exclusivamente con la orina en un $90 \%$ en forma de alantoína y ácido úrico. Su semivida de eliminación es de 0.85 horas y sus efectos adversos generales son leves y transitorios tanto en adultos como en edad pediátrica. [11] $-[17]$.

En la actualidad no existe evidencia de algún estudio piloto del uso del Metisoprinol en el manejo del covid -19 .

El objetivo del presente estudio es determinar la eficacia del uso del metisoprinol en pacientes con covid-19, especificándose la edad y sexo, la presencia de comorbilidades posibles de los pacientes a tratar, para posteriormente clasificar el cuadro clínico de los pacientes en 2 grupos de 30 personas cada uno, quedando así en un grupo experimental y el grupo control previo al tratamiento y posterior al mismo, determinar los hallazgos de laboratorio e imagenológico del grupo experimental y el grupo que solo recibió el tratamiento convencional propuesto en trabajo de investigación, especificar las probables complicaciones presentadas en pacientes de ambos grupos en estudio con Covid-19, en el periodo entre marzo - abril del 2020, en la ciudad de Guayaquil, Ecuador.

\section{III.METODOLOGÍA}

El presente estudio es tipo ensayo clínico aleatorio controlado, diseño analítico de carácter experimental, prospectivo y progresivo. Se evaluó una población de 60 pacientes distribuida en 2 grupos de 30 (grupo experimental y un grupo control) con edades comprendidas de 2 meses a 71 años de edad de ambos sexos, los cuales presentaron signos y síntomas de SARS-CoV-2 y S02 (saturación de oxigeno) mayor de $90 \%$ respirando aire ambiente con comorbilidades controladas en fase clínica menor de 15 días, asistidos en consulta médica a 
domicilio en la ciudad de Guayaquil, Ecuador entre el periodo de marzo - abril de 2020. Las muestras son de tipo no probabilística supeditada a la presencia de criterios de inclusión y lapso de investigación.

Por tratarse de una investigación experimental se realizó un censo muestrario diario durante 6 semanas de datos de la historia clínica, la cual se completó con una ficha de recolección de datos que consta de 6 partes y fue diseñada considerando la operacionalización de variables, realizándose bajo el consentimiento informado de recibir tratamiento médico experimental con metisoprinol y control para realizar dicha investigación.

Se elaboró un instrumento para la recolección de datos aportados por el paciente y evaluaciones medicas realizadas, el cual se conformó de la siguiente manera; se describió las comorbilidades de acuerdo a las patologías de los pacientes (parte I), se clasifico el cuadro clínico que presentaron (parte II), se indicó la saturación de oxígeno del paciente (parte III), se plasmó el resultado de las pruebas de laboratorio de covid-19 dado por rRT-PCR de hisopado nasofaríngeo (parte IV), se describió los resultados tomográfícos de tórax (parte $\mathrm{V}$ ) y tratamiento empleado así como complicaciones presentadas (parte VI).

Ahora bien, el tratamiento que recibió el grupo experimental se basó en metisoprinol vía oral, a dosis pediátrica $50 \mathrm{mg} / \mathrm{kg} /$ día divido en 4 tomas diarias por 4 días luego cada 8 horas hasta completar los 14 días y en adulto 1 gr vía oral única dosis luego $500 \mathrm{mg}$ cada 6 horas por 4 días luego cada 8 horas por 14 días, azitromicina vía oral en pediátricos $10 \mathrm{mg} / \mathrm{kg} /$ día diario por 5 días y en adultos $500 \mathrm{mg}$ tableta diaria por 5 días, amoxicilina + ácido clavulanico vía oral a dosis pediátrica $25 \mathrm{mg} /$ $\mathrm{kg} /$ día divido cada 12 horas por 7 días y en adultos $1 \mathrm{~g}$ cada 12 horas por 7 días, dexametasona en pediátricos $0.4 \mathrm{mg} / \mathrm{kg} /$ día IM diario por 3 días y en adulto $16 \mathrm{mg}$ endovenosa única dosis luego $8 \mathrm{mg}$ Intramuscular diario por 3 dosis rotándolo a Prednisona en pediátricos $1 \mathrm{mg} /$ $\mathrm{kg}$ /día y en adulto $25 \mathrm{mg}$ cada 12 horas vía oral bajando a dosis piramidal por 7 días, ácido ascórbico vía oral en pediátrico $20 \mathrm{mg} / \mathrm{kg} /$ día y en adulto $1.5 \mathrm{gr}$ vía oral cada 12 horas por 14 días; el tratamiento que recibió el grupo control fue todo lo descrito anteriormente con excepción del metisoprinol.

Además, se realizó controles previos y posteriores al tratamiento médico en el grupo experimental y control basados en laboratorios (Rrt-PCR de hisopado nasofaríngeo) como estudios tomográficos de tórax con vigilancia médica diaria por 6 semanas consecutivos del cuadro clínico y controles de la saturación de oxigeno por cada valoración. De la misma manera, se determinar las posibles complicaciones o recaídas de los pacientes.

Los datos obtenidos se analizaron a través de técnicas estadísticas de tendencia central tipo rango, promedio $(\mathrm{X})$, frecuencia $(\mathrm{F})$ y porcentaje $(\%)$; la correlación se estableció mediante métodos estadísticos de tipo riesgo relativo, considerándose diferencias estadísticamente significativas cuando el valor RR sea igual o menor a 0.57 , cuyos resultados se expresarán en tablas.

\section{IV.RESULTADOS}

Esta investigación tuvo como objetivos; determinar la eficacia del metisoprinol y comparar los resultados obtenidos entre el grupo experimental y el grupo control (cuadro clínico; dado por signos, síntomas y saturación de oxígeno, laboratorios, estudios de imágenes y complicaciones) antes y después del tratamiento, describir las características biológicas y comorbilidades de los pacientes, cuyos datos fueron analizados a través de tablas, porcentajes, frecuencias y cálculo de algunas medidas (promedio, tendencia central, variabilidades).

Esta experiencia investigativa se llevó acabo con una población de 60 pacientes (ver tabla 1) de ambos sexos (ver tabla 2) con virus SARS-COV 2 confirmado, asistidos en consulta médica en la ciudad en la Guayaquil, Provincia de Guayas, Ecuador, durante el periodo de marzo- abril de 2020.

Las características biológicas de los pacientes son las siguientes; una edad promedio de 33.28 años, con una desviación estándar de \pm 16.07 años para una minina edad de 2 meses y una máxima de 71 años, con una amplitud de 70.8 años, de los cuales el 35\% presenta entre 21 a y 40 años (ver tabla I).

TABLA I. Edades de los pacientes estudiados.

\begin{tabular}{ccc}
\hline Edad & Frecuencia & Porcentaje \\
\hline 0 mes-20a & 10 & 16.67 \\
$21 \mathrm{a}-40 \mathrm{a}$ & 35 & 58.33 \\
$41 \mathrm{a}-60 \mathrm{a}$ & 10 & 16.67 \\
$61 \mathrm{a}-80 \mathrm{a}$ & 05 & 08.33 \\
\hline
\end{tabular}


Con respecto al sexo de los pacientes, hay una distribución asimétrica con tendencia al sexo masculino en un $53.33 \%$ con un total de 32 pacientes y $46.67 \%$ para el sexo femenino correspondiente a 28 (ver tabla II).

TABLA II. Según el sexo de los pacientes estudiados.

\begin{tabular}{ccc}
\hline Sexo & Frecuencia & Porcentaje \\
\hline Femenino & 28 & 46.67 \\
Masculino & 32 & 53.33 \\
Total & 60 & 100 \\
\hline
\end{tabular}

La población identificada en el presente estudio presenta una serie de comorbilidades controladas tales como; enfermedad cardiovascular (hipertensión arterial), diabetes mellitus tipo 2, hipotiroidismo, EPOC (enfermedad pulmonar obstructiva crónica), asma bronquial, neoplásicos (cáncer de colon, linfoma cutáneo), enfermedad digestiva (trastorno de malabsorción gastrointestinal, ulcera gastroduodenal), enfermedad renal crónica del estadio 3-5, metabólicas (sobrepeso y obesidad mórbida) y dermatológicas (dermatitis atópica), (ver tabla III).

TABLA III. Comorbilidades presentes en los pacientes estudiados.

\begin{tabular}{lcc}
\hline \multicolumn{1}{c}{ Patologías } & Frecuencia & Porcentaje \\
\hline Respiratorias & 06 & 10.00 \\
Endocrinológicas & 17 & 28.33 \\
Cutáneo mucosas & 07 & 11.67 \\
Renales & 10 & 16.67 \\
Cardiovasculares & 35 & 58.33 \\
Gastrointestinales & 03 & 05.00 \\
Oncológicas & 02 & 03.30 \\
& & \\
\hline
\end{tabular}

La muestra experimental recibió un ciclo de Metisoprinol vía oral, corticoides, ácido ascórbico, inmunomoduladores, antibioticoterapia y la muestra control recibió la atención habitual sin dicho antiviral por 14 días.

Previo al tratamiento tanto en el grupo experimental (ver tabla IV A) como en el grupo control (ver tabla IV B) presentaron diversidades en signos y síntomas, los cuales fueron clasificados por sistemas, dados por: fiebre, tos seca o productiva, astenia, hiporexia, mialgia, artralgia, escalofríos, mareos, visión borrosa, disnea, sincope, cefalea, odinofagia, anosmia, ageusia, diarrea, rinorrea hialina anterior, dolor pleurítico, conjuntivitis viral. Se observó expresión cutánea con los siguientes patrones: erupción purpurica bilateral axilar, erupción maculopapular y erupción urticariforme en tronco y miembros, eritema multiforme en palmas y tronco, erosivo en mucosa y maculas violáceas en manos y pies, patrón pseudo vesicular generalizado que fueron catalogados como síntomas sospechosos de infección por SARS-CoV-2 según criterio clínico. (ver figura. 1).

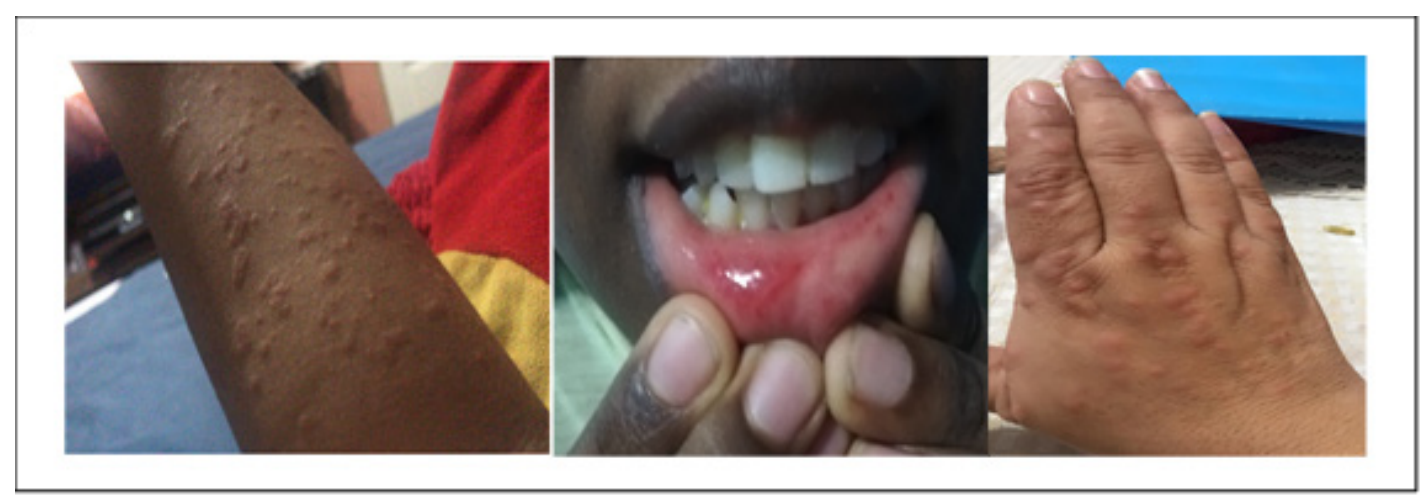

Figura. 1. Lesiones en piel por SARS-CoV-2. 
TABLA IV A. Cuadro clínico de covid -19 presentado por el grupo experimental durante el estudio con tratamiento del metisoprinol

\begin{tabular}{lcccccc}
\hline $\begin{array}{c}\text { Signos y síntomas } \\
\text { por sistemas }\end{array}$ & $\begin{array}{c}\text { Fase } \\
\text { Inicial } \\
<7 \text { días }\end{array}$ & Porcentaje & $\begin{array}{c}\text { Fase } 2 \\
8-14 \text { días }\end{array}$ & Porcentaje & $\begin{array}{c}\text { Fase } 3 \\
>15 \text { días }\end{array}$ & Porcentaje \\
\hline Neurológico & Frecuencia & & Frecuencia & \multicolumn{3}{c}{ Frecuencia } \\
Respiratorio & 12 & 40 & 02 & 6.67 & 00 & 00 \\
Osteomuscular & 30 & 100 & 02 & 6.67 & 00 & 00 \\
Infeccioso & 25 & 83.33 & 00 & 00 & 00 & 00 \\
Gastrointestinal & 29 & 96.67 & 00 & 00 & 00 & 00 \\
Cutáneo mucosa & 20 & 66.67 & 00 & 00 & 00 & 00 \\
\hline
\end{tabular}

TABLA IV B. Cuadro clínico de Covid -19 presentado por el grupo control durante el estudio con tratamiento sin metisoprinol

\begin{tabular}{lcccccc}
\hline $\begin{array}{c}\text { Signos y síntomas } \\
\text { por sistemas }\end{array}$ & $\begin{array}{c}\text { Fase } \\
\text { Inicial } \\
<7 \text { días }\end{array}$ & Porcentaje & $\begin{array}{c}\text { Fase } 2 \\
8-14 \text { días }\end{array}$ & Porcentaje & $\begin{array}{c}\text { Fase 3 } \\
>15 \text { días }\end{array}$ & Porcentaje \\
\hline Neurológico & Frecuencia & & Frecuencia & \multicolumn{3}{c}{ Frecuencia } \\
\hline Respiratorio & 20 & 66.67 & 15 & 50 & 10 & 33.33 \\
Osteomuscular & 30 & 100 & 30 & 100 & 20 & 66.67 \\
Infeccioso & 15 & 50 & 13 & 43.33 & 10 & 33.33 \\
Gastrointestinal & 29 & 96.67 & 18 & 60 & 07 & 23.33 \\
Cutáneo mucosa & 10 & 33.33 & 08 & 26.67 & 04 & 13.33 \\
\hline
\end{tabular}

Se empleó como marcador pronostico y manejo ex- $\quad 90 \%$ en un $23.33 \%$ y el grupo experimental (ver tabla tra hospitalario la saturación de oxigeno mayor de $90 \%$ VA) presentó por encima de $90 \%$, correspondiendo el donde se pudo evidenciar pacientes del grupo control $100 \%$ de la muestra. (ver tabla VB) saturaciones de oxigeno por debajo de

TABLA V A. Saturación de oxigeno presentada por el grupo experimental durante el estudio

\begin{tabular}{ccccccr}
\hline & Fase & & Fase 2 & Fase 3 & \\
Saturación de Oxigeno & $\begin{array}{c}\text { Inicial } \\
<7 \text { días }\end{array}$ & Porcentaje & $8-14$ días & Porcentaje & $>15$ días & Porcentaje \\
\hline$>90 \%$ & 30 & 100 & 30 & 100 & 30 & 100 \\
$<90 \%$ & 00 & 00 & 00 & 00 & 00 & 00 \\
\hline
\end{tabular}

TABLA V B. Saturación de oxigeno presentada por el grupo control durante el estudio

\begin{tabular}{ccccccc}
\hline $\begin{array}{c}\text { Saturación } \\
\text { de Oxigeno }\end{array}$ & $\begin{array}{c}\text { Fase Inicial } \\
<7 \text { días } \\
\text { Frecuencia }\end{array}$ & Porcentaje & $\begin{array}{c}\text { Fase } 2 \\
8-14 \text { días } \\
\text { Frecuencia }\end{array}$ & Porcentaje & $\begin{array}{c}\text { Fase } 3 \\
>15 \text { días }\end{array}$ & Porcentaje \\
\hline$>90 \%$ & 30 & 100 & 26 & 86.67 & 27 & 90 \\
$<90 \%$ & 00 & 00 & 04 & 13.33 & 03 & 10 \\
\hline
\end{tabular}


Se realizaron pruebas de hisopado nasofaríngeo antes del tratamiento en ambos grupos donde el 100\% fueron positivos rRT-PCR para Covid-19. Comparado a las pruebas realizadas posterior a los 14 días de tratamien- to, el grupo experimental presento solo el $10 \%$ positivo dado por 3 pacientes (ver tabla VI A) y el grupo control el $66.67 \%$ positivo (ver tabla VI B) correspondiente a 20 pacientes.

TABLA VI A. Laboratorios realizados al grupo experimental durante el estudio.

\begin{tabular}{llccc}
\hline Pruebas & $\begin{array}{l}\text { Fase Inicial } \\
<7 \text { dias }\end{array}$ & Porcentaje & $\begin{array}{l}\text { Fase } 3 \\
>15 \text { días }\end{array}$ & Porcentaje \\
\hline $\begin{array}{l}\text { rRT-PCR hisopado } \\
\text { Nasofaríngeo }\end{array}$ & $30(+)$ & $100 \%$ & $03(+)$ & $10 \%$ \\
\hline
\end{tabular}

TABLA VI B. Laboratorios realizados al grupo control durante el estudio

\begin{tabular}{lcccc}
\hline Pruebas & $\begin{array}{l}\text { Fase Inicial } \\
<7 \text { dias }\end{array}$ & Porcentaje & $\begin{array}{l}\text { Fase } 3 \\
>15 \text { días }\end{array}$ & Porcentaje \\
\hline $\begin{array}{l}\text { rRT-PCR hisopado } \\
\text { Nasofaríngeo }\end{array}$ & $30(+)$ & $100 \%$ & $20(+)$ & $66.67 \%$ \\
\hline
\end{tabular}

Por otra parte, todos los pacientes presentaron síntomas respiratorios (ver tabla VIIA) previo al tratamiento, motivo por el cual se realizaron estudios tomográficos de tórax, evidenciándose imágenes en 20 pacientes en vidrio esmerilado, 04 pacientes con signos de consolidación pulmonar, 34 pacientes con broncograma aéreo y 60 pacientes con reforzamiento vascular perihiliar bilateral, donde se clasifico de acuerdo a los hallazgos 34 bronquitis virales y 26 neumonías virales. Se pudo observar que posterior a los 14 días de tratamiento con metisoprinol se obtuvo el $96.66 \%$ de mejoría imagenológica (ver tabla VIIB) y en el grupo control (ver tabla VIIB) persistió imágenes patológicas el $66.67 \%$.

TABLA VII A. Estudios imagenológicos realizado en la fase inicial antes del tratamiento en ambos grupos.

\begin{tabular}{llccc}
\hline Tomografía de pulmón & $\begin{array}{l}\text { Grupo } \\
\text { experimental }\end{array}$ & Porcentaje & Grupo control & Porcentaje \\
\hline Normal & 0 & 0 & 0 & 0 \\
Patológico & 30 & 100 & 30 & 100 \\
\hline
\end{tabular}

TABLA VII B. Estudios imagenológicos realizado en la fase $3>15$ días después del tratamiento en ambos grupos.

\begin{tabular}{lcccl}
\hline Tomografía de pulmón & Grupo experimental & Porcentaje & Grupo control & Porcentaje \\
\hline Normal & 29 & 96.67 & 10 & 33.33 \\
Patológico & 01 & 03.33 & 20 & 66.67 \\
\hline
\end{tabular}

Se comparó la persistencia de signos y síntomas de ambos grupos para demostrar la eficacia del metisoprinol del protocolo tratado, a través del cálculo de riesgo relativo, en el cual se compara los riesgos entre grupos y surge del cociente entre el riesgo atribuible en el grupo experimental y el grupo control (ver tabla VII). 
TABLA VIII. Comparación según cuadro clínico que presentaron los pacientes de ambos grupos en la fase final > 15 días.

\begin{tabular}{lcccc}
\hline Covid-19 & Con clínica & Porcentaje & Sin Clínica & Porcentaje \\
\hline Metisoprinol & 03 & 10 & 27 & 90 \\
Protocolo sin & 20 & 66.67 & 10 & 33.33 \\
Metisoprinol & & & & \\
Riesgo Relativo $=$ & & $\frac{03 / 30}{20 / 30}$ & $\frac{0.1}{2}$ & RR $=0.14$ \\
& & & \\
\hline
\end{tabular}

Dicha comparación demostró la poca posibilidad de persistir los signos y síntomas en los pacientes que recibieron metisoprinol después de los 14 días. La persistencia mínima de dicha clínica del grupo experimental corresponde a casos de dermatología donde los pacientes presentaron mejoría del prurito, lesiones en relieve, mejoría de la extensión de la lesión, pero con presencia de hiperpigmentación del área afectada compatible con máculas. Cabe destacar que el patrón de piel por lo general su mejoría es lenta. Además, el paciente de 2 meses de edad estuvo en el grupo control, por lo que presento escasa mejoría.

De acuerdo al riesgo de desaturarse por debajo de 90 porciento, la posibilidad es nula en aquellos pacientes que recibieron el metisoprinol durante el estudio (ver tabla IX).

TABLA. IX Comparación de la saturación oxigeno que presentaron los pacientes de ambos grupos en la fase 2 - 3 durante el periodo de tratamiento.

\begin{tabular}{llccc}
\hline \multicolumn{1}{c}{ COVID-19 } & SO2 $>90$ & Porcentaje & SO2 $<90$ & Porcentaje \\
\hline Metisoprinol & 30 & 100 & 00 & 00 \\
Protocolo sin & 23 & 76.67 & 07 & 23.33 \\
Metisoprinol & & & & \\
Riesgo & & $\underline{0 / 30}$ & $\underline{00}$ & RR:0 \\
Relativo $=$ & & $7 / 30$ & 0.23 & \\
\hline
\end{tabular}

Ahora bien, los resultados referentes a los hisopados nasofaríngeos (ver tabla $\mathrm{X}$ ) realizados posterior al tratamiento nos indica que los pacientes con covid-19 tratados con metisoprinol tienen casi nula la posibilidad de persistir la infección en comparación con los que no recibieron dicho antiviral.

TABLA X. Comparación de los resultados de rRT-PCR del hisopado nasofaríngeo del grupo experimental y grupo control posterior a los 15 días.

\begin{tabular}{|c|c|c|c|c|}
\hline COVID-19 & $\begin{array}{c}\text { rRT-PCR } \\
(-) \\
\text { Frecuencia }\end{array}$ & Porcentaje & $\begin{array}{l}\text { rRT-PCR } \\
\quad(+) \\
\text { Frecuencia }\end{array}$ & Porcentaje \\
\hline Metisoprinol & 28 & 93.33 & 02 & 06.67 \\
\hline $\begin{array}{l}\text { Protocolo sin } \\
\text { metisoprinol }\end{array}$ & 20 & 66.67 & 10 & 33.33 \\
\hline Riesgo Relativo $=$ & & $\frac{02 / 30}{10 / 30}$ & $\begin{array}{l}0.067 \\
0.333\end{array}$ & 0.20 \\
\hline
\end{tabular}

Los resultados con relación al beneficio del tratamiento experimental, nos indica que es mínimo el riesgo de persistir las lesiones pulmonares en covid-19 en comparación con los que no recibieron dicho antiviral (ver tabla XI). 
TABLA XI. Comparación de los resultados de tomografía axial computarizada de pulmón simple del grupo experimental y grupo posterior a los 15 días.

\begin{tabular}{lcccc}
\hline COVID-19 & $\begin{array}{c}\text { TAC de pulmón } \\
\text { sin lesiones } \\
\text { Frecuencia }\end{array}$ & Porcentaje & $\begin{array}{c}\text { TAC de pulmón } \\
\text { con lesiones } \\
\text { Frecuencia }\end{array}$ & Porcentaje \\
\hline Metisoprinol & 29 & 96.67 & 01 & 03.33 \\
$\begin{array}{l}\text { Protocolo sin } \\
\text { metisoprinol }\end{array}$ & 04 & 13.33 & 26 & 86.67 \\
Riesgo Relativo $=$ & & $\underline{01 / 30}$ & $\underline{0.033}$ & 0.038 \\
\hline
\end{tabular}

En las siguientes imágenes se puede observar los cambios presentados en algunos de los pacientes estudiados y tratados con metisoprinol:

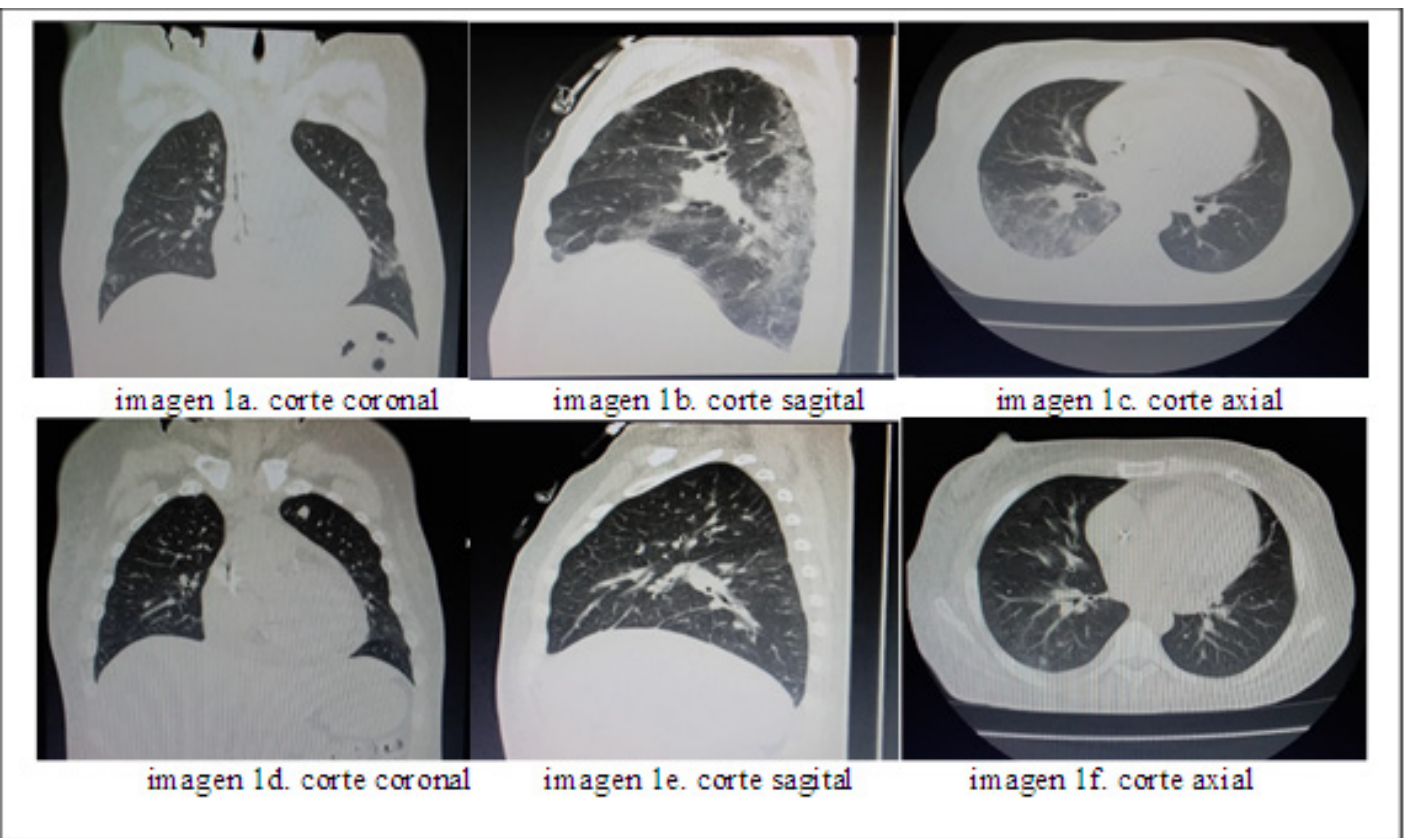

Figura 2. Tomografía axial computarizada simple de paciente con SARS-CoV-2

Se evidencia en la figura 2, imágenes tomográficas axiales computarizadas de pulmón, demostrando el diagnóstico y seguimiento de casos confirmados por covid-19. Paciente femenina con antecedentes de insuficiencia renal crónica terminal secundaria a glomeruloangioesclerosis y diabetes mellitus tipo 2. Las imágenes $1 \mathrm{~A}, \mathrm{~B}$ y $\mathrm{C}$ corresponden a la fase inicial del $\mathrm{Se}$ evidencia en la figura 3 imágenes tomográfícas axiales computarizadas de tórax; demostrando el diagnóstico y seguimiento de casos confirmados por covid-19. Paciente masculino con antecedentes de enfermedad pulmonar obstructiva crónica (EPOC) y cardiovasculares, donde las imágenes $2 \mathrm{~A}, \mathrm{~B}$ y $\mathrm{C}$ corresponden a la fase inicial del tratamiento, observándose engrosamientos 


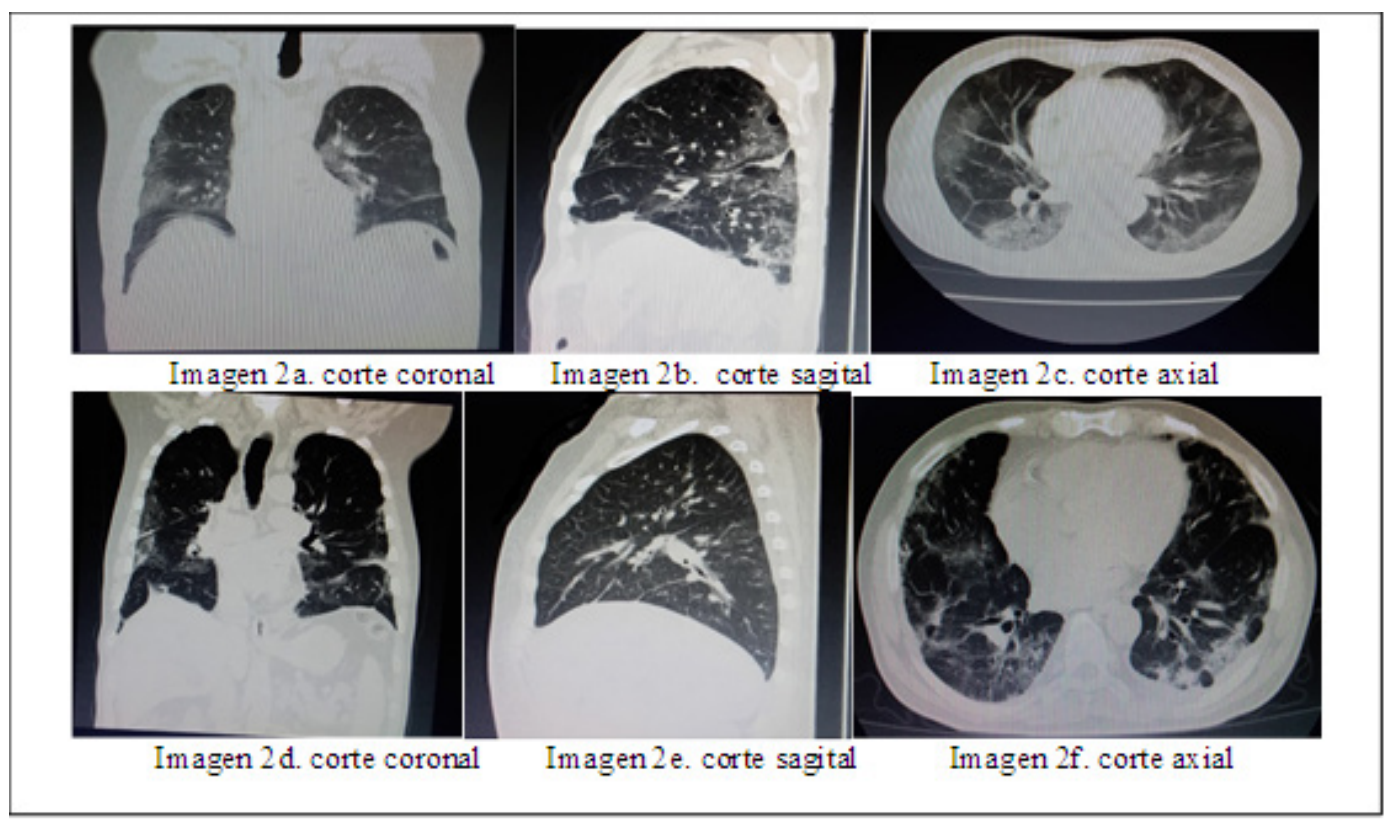

Figura 3. Tomografía axial computarizada simple de paciente con SARS-CoV-2

septales interlobulillares, broncograma aéreo, reforzamiento vascular parahiliar bilateral, consolidación con "vidrio esmerilado", imágenes tabicadas y presencia de bula. Las imágenes $2 \mathrm{D}, \mathrm{E}, \mathrm{F}$ se observa bronquiectasias tabicadas, bula y mejoría de lesiones en vidrio esmerilado posterior al uso por 14 días del Metisoprinol.

Las complicaciones fueron evidenciadas en el grupo control, dada por desaturación de oxigeno por debajo de $90 \%$ en un $23.33 \%$ y persistencia del cuadro respiratorio en un $66.67 \%$, por lo que 07 (siete) pacientes ameritaron ser trasladados a centros médicos hospitalarios para manejo ventilatorio no invasivo o mecánico. El resto de los 23 pacientes se les hizo seguimiento hasta cumplir 6 semanas con resolución de las sintomatologías. El 80\% del grupo control presentó taquicardia sinusal, ameritando tratamiento a base de betabloqueantes.

\section{V.CONCLUSIONES}

1.El presente protocolo demostró mejoría en los controles imagenológicos para SARS-CoV-2 en el día 15 en un $96.67 \%$ en el grupo experimental y en el grupo control solo el $13.33 \%$. El $93.33 \%$ del grupo experimental presentó negatividad en los resultados de laboratorio y el $66.67 \%$ en el grupo control al finalizar el tratamiento. La saturación de oxígeno en el grupo experimental se mantuvo por encima del $90 \%$ durante el estudio realizado.

2.Las complicaciones solo se evidenciaron en el grupo control dado por el $23.33 \%$, los cuales se refirieron a centros hospitalarios por complicaciones respiratorias basadas en saturación menor de 90 \% y mala mecánica ventilatoria.

3.Debe tomarse en cuenta las comorbilidades de los pacientes, el estado hemodinámico que se encuentren propio de la enfermedad asociada y las sintomatologías observadas para SARS-CoV-2 para indicar dicho protocolo, ya que en algunos casos de tener condiciones hemodinámicas inestables podrían ameritar manejo hospitalario.

4.Se sugiere realizar más estudios con metisoprinol en pacientes con covid -19 , ya que los resultados del tratamiento experimental fueron favorecedores.

\section{REFERENCIAS}

[1]"Interpretación de las pruebas diagnósticas frente a sars-cov-2", Instituto de Salud Carlos III, ponencia, versión 2, 2020.

[2]X.Yang, Y.Yu, J.Xu, S. Huaging, X. Jia'an, L.Hong, et al, "Clinical course and outcomes of critically ill patients with SARS-CoV-2 pneumonia in Wuhan, China: a single-centered, retrospective, observational study". The Lancet Respiratory Medicine, Vol 8. pp. 475-481, May 2020.

[3]D.Wang, B.Hu, C.Hu, et al, "Clinical Characteristics of 138 Hospitalized Patients With 2019 Novel Coronavirus-Infected Pneumonia in Wuhan, China". JAMA, Vol.323, 11, pp. 1061-1069, March 2020.

[4]"Protocolo de investigación de los primeros casos y sus contactos directos (FFX) de la enfermedad por Coronavirus 2019 (COVID-19)", Organización Mundial 
de la Salud, versión 2, 2020.

[5]"Manejo clínico del COVID-19: atención hospitalaria", Ministerio de Sanidad Gobierno de España, documento técnico, 2020.

[6]L. Baden, and E. Rubin, "Covid-19 - The Search for Effective Therapy." The New England journal of medicine, vol. 382, 19, pp.1851-1852, March 2020.

[7]B. Cao, Y. Wang, D. Wen, et al, “A Trial of Lopinavir-Ritonavir in Adults Hospitalized with Severe Covid-19", The New England journal of medicine, vol. 382, 19, pp.1787-1799

[8]"Report of the WHO-China Joint Mission on Coronavirus Disease 2019 (COVID-19)", World health Organization, report, 2020.

[9]S. Mallapaty, "Mystery deepens over animal source of coronavirus", Nature, vol. 579, pp.18-19, March 2020.

[10]TT. Lam, N. Jia, YW. Zhang, et al, "Identifying SARS-CoV-2-related coronaviruses in Malayan pangolins", Nature, March 2020.

[11]Información Numero 032 de la situación nacional frente a la Emergencia Sanitaria por el \#COVID19E-

\section{RESUMEN CURRICULAR}

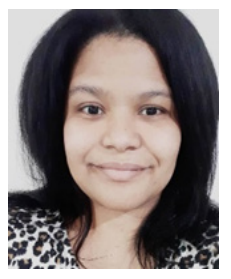

Migled José Borges Quero, Médico Cirujano egresada Universidad Nacional Experimental "Francisco de Miranda", Especialista en Neurocirugía egresada del Hospital Universitario "Dr. Alfredo Van Grieken", Coro, Venezuela. Miembro de la AO Spine. Médico en el Área Covid-19 del Hospital General Monte Sinaí, Guayaquil, Ecuador.

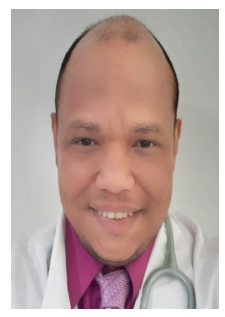

José Martin Borges Quero, Médico Cirujano Especialista en Cirugía General egresado Universidad Nacional Experimental "Francisco de Miranda", Coro, Venezuela. Médico en el Área Covid-19 del Hospital General Monte Sinaí, Guayaquil, Ecuador. cuador \# QuedateEnCasa, Gestión de Riesgos de Ecuador, comunicado oficial, marzo 2020.

[12]L.Saif, "Animal coronavirus: lessons for SARS", National Academies Press, 2004.

[13]F. García, "Futuro de los medicamentos antivirales", Hospital General y Docente INSALUD, Guadalajara.

[14]"Farmaceuticos.docx - Metisoprinol", Curse Hero Farmaceuticos.dox.

[15]W. Lasek, M. Janyst, R. Wolny, L. Zapała, K. Bocian, N. Drela, "Immunomodulatory effects of inosine pranobex on cytokine production by human lymphocytes”. Acta Pharm. Vol. 65, 2, pp. 171-180, June 2015. [16]JN. Zurita-Cruz JN, H. Márquez-González, G. Miranda-Novales, MA. Villasís-Keever, "Estudios experimentales: diseños de investigación para la evaluación de intervenciones en la clínica”, Rev Alerg, vol. 65, 2, pp. 178-186, June 2018.

[17]E. Sandoya, "Cómo analizar un ensayo clínico: el estudio ASCOT-BPLA”, vol.21, 1, pp.35-47, July 2006.

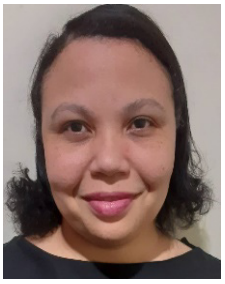

Migledys Isabel Borges Quero, Médico Cirujano egresada Universidad Nacional Experimental "Francisco de Miranda", Especialista en Nefrología de Adulto egresada del Hospital Universitario "Dr. Alfredo Van Grieken", Coro, Venezuela. Nefrólogo del Hospital General "Monte Sinaí" en el área de diálisis y emergencia Covid-19, Guayaquil, Ecuador.

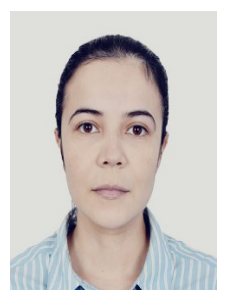

Rosangel Yakery Bastidas Campos, Médico Cirujano egresada de la Universidad Centrooccidental Lisandro Alvarado, residencia en Medicina Interna en el Hospital Central "Placido D. Rodríguez Rivero", especialista en Dermatología de la Universidad de Carabobo, Docente de la Universidad Pedagógica Experimental Libertador, Valencia, Venezuela. Dermatóloga en el Hospital General Monte Sinaí, Guayaquil, Ecuador. 